\title{
Occurrence of Comorbidities before and after Soft Tissue Sarcoma Diagnosis
}

\author{
Myrthe P. P. van Herk-Sukel, ${ }^{1}$ Sumitra Shantakumar, ${ }^{2}$ Lucy I. H. Overbeek, ${ }^{3}$ \\ Hester van Boven, ${ }^{4}$ Fernie J. A. Penning-van Beest, ${ }^{1}$ and Ron M. C. Herings ${ }^{1,5}$ \\ ${ }^{1}$ PHARMO Institute for Drug Outcomes Research, P.O. Box 85222, 3508 AE Utrecht, The Netherlands \\ ${ }^{2}$ Oncology Biometrics and Epidemiology, Oncology R\&D, GlaxoSmithKline, RTP, NC 27709, USA \\ ${ }^{3}$ The Nationwide Network and Registry for Histo- and Cytopathology in The Netherlands, Foundation PALGA, \\ Utrecht, The Netherlands \\ ${ }^{4}$ The Netherlands Cancer Institute-Antoni van Leeuwenhoek Hospital (NKI-AVL), 1066 CX Amsterdam, The Netherlands \\ ${ }^{5}$ Department of Medical Informatics, Erasmus University Medical Centre, 3015 GE Rotterdam, The Netherlands
}

Correspondence should be addressed to Myrthe P. P. van Herk-Sukel, myrthe.van.herk@pharmo.nl

Received 5 March 2012; Accepted 26 March 2012

Academic Editor: Clement Trovik

Copyright ( 2012 Myrthe P. P. van Herk-Sukel et al. This is an open access article distributed under the Creative Commons Attribution License, which permits unrestricted use, distribution, and reproduction in any medium, provided the original work is properly cited.

\begin{abstract}
Background. Data is limited on the burden of common comorbidities, such as cardiovascular disease (CVD), respiratory disease and diabetes, or comorbidities related to cancer and its treatment, such as anemia and depression, in patients with soft tissue sarcoma (STS). Patients and Methods. From the Dutch Pathology Registry linked to the PHARMO database (including data on drug use and hospitalizations), 533 patients with STS were selected during 2000-2007 and matched 1:10 to cancer-free controls. The occurrences of comorbidities were assessed in the 12 months before and after STS diagnosis. Results. STS patients were 2-4 times more likely to have comorbidities at diagnosis compared with cancer-free controls. The incidence of CVD, anemia, and depression after STS diagnosis differed significantly from cancer-free controls and decreased during followup from 40-124 per 1,000 person-years (py) during the first six months to 11-38 per 1,000 py more than 12 months after diagnosis. The incidence of respiratory disease and diabetes among STS patients remained stable during followup (5-21 per 1,000 py) and did not differ significantly from cancer-free controls. Conclusions. STS patients were more likely to have comorbidities before cancer diagnosis and to develop CVD, anemia, and depression after diagnosis compared to cancer-free controls.
\end{abstract}

\section{Introduction}

Soft tissue sarcomas (STSs) are a rare and heterogeneous group of tumors arising from mesenchymal tissue [1]. They account for less than $1 \%$ of all new malignancies diagnosed in adults in Europe [2, 3]. STSs show a broad range of differentiation and may arise in, for example, fat (liposarcoma), muscle (smooth muscle: leiomyosarcoma and striated muscle: rhabdomyosarcoma), and fibrous tissue (e.g., fibrosarcoma, malignant fibrous hystiocytoma, and dermatofibrosarcoma) [1]. The most common treatment for STS is surgical resection with or without radiation therapy and chemotherapy is administered when metastases are present [4-6].
Little epidemiologic data on STS is available due to large variations in tumor biology, histology, location, stage at presentation, and the relative rarity of these tumors [7]. The development of STS has been shown to be associated with environmental factors, immunodeficiency, genetic factors, and viral infection $[8,9]$. Important prognostic factors of STS reported in the literature include tumor size, histology, primary anatomic site, grade, and the presence of metastatic disease $[8,10,11]$. The overall survival of patients with STS has been improving, however this differs per histological subtype $[12,13]$. Many of these patients will have concomitant conditions, which has various clinical implications. Comorbidities are independent determinants of prognosis (regardless of the chosen therapy) and their presence is also 
an indicator of the complexity of the clinical needs of each patient [14].

Previous studies using administrative healthcare databases showed that cardiovascular disease (CVD), respiratory disease, and diabetes are the most common concomitant illnesses in cancer patients $[14,15]$. Currently, there is limited data available that describes the burden of these comorbidities among STS patients. It is important to quantify these comorbidities as these often necessitate modifications of and/or adversely influence the chosen therapy. Moreover, less is known about the impact of the most prevalent cancer symptom: fatigue [16]. Fatigue severely impacts quality of life and functional capacity. The condition itself is difficult to measure, but instead one can study treatable contributing factors like anemia and depression.

This retrospective cohort study describes the prevalence and incidence of comorbidities including cardiovascular disease, respiratory disease, diabetes, anemia, and depression among a population-based cohort of STS patients. These rates were compared to those observed in a matched noncancer control population. In addition, risk factors for developing these morbidities after STS diagnosis were determined.

\section{Methods}

2.1. Data Sources. Data from patients with a STS pathology specimen were obtained from PALGA, the Dutch Nationwide Network and Registry of Histo- and Cytopathology. PALGA contains data of all histological, cytological, and autopsy examinations in The Netherlands [17]. Currently, it contains about 42 million abstracts of all pathology reports with encrypted patient identification and diagnostic terms which are in scope with SNOMED classification. PALGA has achieved complete national coverage since 1990 and is the basis for the Dutch Cancer Registry. Records from PALGA were linked to the PHARMO record linkage system (PHARMO RLS). This linkage has been used in previous published studies $[18,19]$. Data from the PHARMO RLS consist of multiple observational databases linked on a patient level, covering 3 million inhabitants of geographic defined areas in the Netherlands. Databases relevant for this study include the Dutch National Medical Register [20] and the community (out-patient) pharmacy database. The hospital records contain detailed information concerning admissions for more than 24 hours and admissions for less than 24 hours for which a bed is required, including primary and secondary diagnoses, procedures, and dates of hospital admission and discharge. All diagnoses are coded according to the International Classification of Diseases, Ninth Revision, Clinical Modification (ICD-9-CM). The drug dispensing histories from community pharmacies contain data on the dispensed drug, prescriber, dispensing date, amount dispensed, prescribed dose regimens, and thus the duration of use. All drugs are coded according to the Anatomical Therapeutic Chemical (ATC) Classification.

2.2. Study Population. Patients with a record of a STS pathology specimen in the period January 1, 2000 to December 31, 2007 were selected from the PALGA database. We excluded Kaposi's sarcomas (as these are strongly associated with herpesvirus [21], and the 2002 WHO classification of STSs does not classify these tumors as a true malignant sarcoma since there are major uncertainties as to their true biology [22]) and gastrointestinal stromal tumors (GIST; as these tumors are largely driven by activating mutations in the protooncogene KIT, with the protein tyrosine kinase inhibitor imatinib and sunitinib as specific treatments for this tumor [23]). Date of first STS pathology specimen was defined as the cohort entry date. To be able to define comorbidities in recent history, patients needed to have at least 12 months of history in the PHARMO RLS. All patients were followed from cohort entry until end of data-collection in the PHARMO RLS (i.e., the patient moves out of the PHARMO RLS catchment area), death, or end of the study period (December 31, 2008), whichever occurred first.

2.3. Cancer-Free Controls. The selection of the control cohort was stepwise. First, each STS patient was matched $1: 20$ by age and gender with a patient from the PHARMO RLS. Each of these potential controls was assigned the cohort entry date of the STS patient case match. Potential cases could not be selected as controls. Second, we eliminated from the pool of 20 possible controls, any control that did not have 12 months of history before cohort entry date in the PHARMO RLS and/or who had a hospitalization with a primary diagnosis for any cancer (ICD-9-CM codes: 140-239) in the period of ten years before the cohort entry date until December 31, 2008. Finally, out of the remaining controls that fulfilled the above criteria, ten were randomly selected and included in the control cohort.

2.4. Characteristics. We determined gender, age, and duration of followup of the patients included in our study cohort. Topography of the tumor was obtained from PALGA and classified as follows: extremities, head and neck, thorax, abdomen or (retro)peritoneum, and overlapping sites or sites not otherwise specified. Histologic type of STS was also obtained from PALGA and determined by using morphology ICD-O-3 codes (International Classification of Diseases for Oncology codes) [24-26]. In addition, data on treatment in the first six months after STS diagnosis was obtained from the PHARMO RLS. Surgery was assessed based on hospital procedure codes and the use of chemotherapy was defined based on hospital discharge diagnoses (ICD-9-CM code: V581) and/or oral chemotherapies supplied by community pharmacies (ATC code: L01). Data on radiation therapy was not available in the data sources of the PHARMO RLS.

2.5. Comorbidities. Comorbidities were defined via hospital admissions (ICD-9-CM codes) and/or drug dispensings (ATC codes) captured in the PHARMO RLS. Patients were considered to have a comorbidity if they either had been hospitalized for the condition or had been dispensed a medication used to treat the condition twice in a 365-day period. For the calculation of incidence rates, the event date of the first of each comorbidity was defined as the date of the hospitalization or the date of the first dispensing, whichever 
TABLE 1: Characteristics of newly diagnosed patients with soft tissue sarcoma.

\begin{tabular}{|c|c|}
\hline Characteristics & $\begin{array}{c}\text { Patients with soft tissue } \\
\text { sarcoma }(N=533) \\
N(\%)\end{array}$ \\
\hline \multicolumn{2}{|l|}{ Gender } \\
\hline Male & $266(50)$ \\
\hline Female & $267(50)$ \\
\hline \multicolumn{2}{|l|}{ Age in years } \\
\hline$<50$ & $180(34)$ \\
\hline $50-<70$ & $211(40)$ \\
\hline$\geq 70$ & $142(27)$ \\
\hline mean $\pm \mathrm{SD}$ & $56( \pm 20)$ \\
\hline \multicolumn{2}{|l|}{ Location } \\
\hline Extremities & $190(36)$ \\
\hline Head and neck & $77(14)$ \\
\hline Thorax & $97(18)$ \\
\hline Abdomen or (retro)peritoneum & $91(17)$ \\
\hline Overlapping sites and NOS & $78(15)$ \\
\hline \multicolumn{2}{|l|}{ Histology } \\
\hline Fibrosarcoma (ICD-O-3: 8810-4) & $17(3)$ \\
\hline $\begin{array}{l}\text { Malignant fibrous hystiocytoma } \\
\text { (ICD-O-3: 8830) }\end{array}$ & $28(5)$ \\
\hline Dermatofibrosarcoma & $27(5)$ \\
\hline $\begin{array}{l}\text { (ICD-O-3: 8832-3) } \\
\text { Liposarcoma (ICD-O-3: 8850-8) }\end{array}$ & $77(14)$ \\
\hline Leiomyosarcoma (ICD-O-3: 8890-1) & $84(16)$ \\
\hline Rhabdomyosarcoma & $17(3)$ \\
\hline $\begin{array}{l}\text { (ICD-O-3: 8900-1, 8910, 8920) } \\
\text { Synovial sarcoma (ICD-O-3: 9040-3) }\end{array}$ & $9(2)$ \\
\hline $\begin{array}{l}\text { Hemangiosarcoma (ICD-O-3: 912, } \\
913,915)\end{array}$ & $22(4)$ \\
\hline Malignant peripheral nerve sheath & $16(3)$ \\
\hline $\begin{array}{l}\text { tumor (ICD-O-3: 9540, 9560) } \\
\text { Sarcoma, other }\end{array}$ & $63(12)$ \\
\hline Sarcoma, NOS (ICD-O-3: 8800) & $173(32)$ \\
\hline \multicolumn{2}{|l|}{ Treatment $^{1,2}$} \\
\hline Surgery & $437(82)$ \\
\hline Chemotherapy & $55(10)$ \\
\hline
\end{tabular}

SD: standard deviation; NOS: not otherwise specified; ${ }^{1}$ no data on radiotherapy available; ${ }^{2}$ defined during the first six months after soft tissue sarcoma diagnosis.

came first. The following comorbidities were considered: cardiovascular disease, including heart disease, thrombosis, and hypertension (ICD-9-CM code: 410, 411, 413, 414, 425-428, 433, 435 or ATC code: B01, C01-C04, C06$\mathrm{C} 10)$, respiratory disease, including asthma, and chronic obstructive pulmonary disease (ICD-9-CM code: 491-493, 496 or ATC code: R03), diabetes (ICD-9-CM code: 250 or ATC code: A10), anemia (ICD-9-CM code: 280, 281, 283285 or ATC code: B03), or depression (ICD-9-CM code: 296.2, 296.3, 296.82, 298.0, 311, 300.4, 309.0, 309.1, 300.9, V62.84, 960-979, E950-E959, E980-E989 or ATC code:
N06A). Comorbidities were assessed in 12 months, of history and during followup ( 0 to 6 months, 6 to 12 months and 12 months to total followup).

2.6. Analyses. Prevalence proportions in the 12 months before cohort entry were assessed for each comorbidity and expressed with accompanying 95\% confidence intervals (CI). Conditional logistic regression was used to compare the prevalence of the comorbidities between the STS patients and the cancer-free control group. For incidence calculations, patients with a prevalent comorbidity (i.e., in the 12 months prior to cohort entry) were removed from the atrisk population for that specific event. Incidence rates per 1,000 person-years with accompanying 95\% CI based on Byar's approximation [27] were calculated for the three distinct periods of followup time. Cox proportional hazards regression analysis was used to compare the incidence of the comorbidities between STS patients and their cancer-free controls. In addition, Cox proportional hazards regression models were fit to identify independent risk factors for developing cardiovascular disease, anemia, and depression (i.e., the three significantly increased comorbidities after STS diagnosis compared to cancer-free controls) in the complete followup after STS diagnosis. The patient characteristics mentioned under the subsection Characteristics were considered as potential risk factors. All risk factors associated with the outcome in the univariate analyses were included in the multivariate analyses. Statistical significance was defined at an alpha level of 0.05. Data were analyzed using SAS programs that are organized within SAS Enterprise Guide version 4.2 (SAS Institute Inc., Cary, NC, USA). Data management was conducted under UNIX using SAS version 9.2.

\section{Results}

A total of 533 patients with a STS resection specimen between 1 January 2000 and 31 December 2007 were selected from the PALGA database and linked to the PHARMO RLS (Table 1). Mean ( \pm standard deviation: SD) age of these patients was $56( \pm 20)$ years and mean $( \pm S D)$ followup in the PHARMO RLS was $3.1( \pm 2.3)$ years. Most STSs were situated in the extremities $(36 \%)$, followed by the thorax $(18 \%)$ and the abdomen or (retro)peritoneum (17\%). For a large proportion of tumors, histology was not specified $(N=173,32 \%)$. The most common known histological tumor type was leiomyosarcoma $(23 \%(84 / 360))$, followed by liposarcoma $(21 \%(77 / 360))$. Treatment in the first six months after STS diagnosis was mainly surgery (82\%). Chemotherapy was administered to $10 \%$ of the patients included in our study cohort.

Table 2 presents the proportion of patients with comorbidity in the 12 months before STS diagnosis compared to cancer-free controls. The most prevalent comorbidity in STS patients was cardiovascular disease (33\%), followed by respiratory disease $(10 \%)$, diabetes $(7 \%)$, anemia $(6 \%)$, and depression (6\%). Overall, STS patients were twice as likely as the cancer-free control group to have any of the 
TABLE 2: Proportion of patients with comorbidities* 12 months before diagnosis of soft tissue sarcoma, compared to a noncancer population.

\begin{tabular}{lccr}
\hline Comorbidity & $\begin{array}{c}\text { Patients with soft tissue sarcoma } \\
(N=533)\end{array}$ & $\begin{array}{c}\text { Cancer-free control cohort } \\
(N=5,330)\end{array}$ & $\begin{array}{c}\text { Odds ratio } \\
(95 \% \mathrm{CI})\end{array}$ \\
\hline Cardiovascular disease & $N(\%)$ & $1,148(22)$ & $2.0(1.7-2.5)$ \\
Respiratory disease & $178(33)$ & $262(5)$ & $2.2(1.6-3.0)$ \\
Diabetes & $54(10)$ & $212(4)$ & $1.8(1.2-2.6)$ \\
Anemia & $36(7)$ & $92(2)$ & $3.6(2.4-5.5)$ \\
Depression & $31(6)$ & $177(3)$ & $2.0(1.4-2.9)$ \\
\hline
\end{tabular}

95\% CI: 95\% confidence interval; * comorbidity defined as either at least 2 dispensings of a relevant drug or a hospitalization for that condition before soft tissue sarcoma diagnosis.

TABLE 3: Incidence rates of comorbidities* stratified by followup time since diagnosis of soft tissue sarcoma, compared to a noncancer population.

\begin{tabular}{|c|c|c|c|c|c|c|c|}
\hline & \multicolumn{3}{|c|}{ Patients with soft tissue sarcoma } & \multicolumn{3}{|c|}{ Cancer-free control cohort } & \multirow{2}{*}{$\begin{array}{l}\text { Hazard ratio } \\
(95 \% \mathrm{CI})\end{array}$} \\
\hline & Events & $\begin{array}{c}\text { Followup } \\
\text { PY }\end{array}$ & $\begin{array}{l}\text { IR per } 1,000 \\
\text { PY }(95 \% \text { CI })\end{array}$ & Events & $\begin{array}{c}\text { Followup } \\
\text { PY }\end{array}$ & $\begin{array}{l}\text { IR per } 1,000 \\
\text { PY }(95 \% \text { CI })\end{array}$ & \\
\hline \multicolumn{8}{|l|}{0 to 6 months after diagnosis } \\
\hline Cardiovascular disease & 20 & 161 & $124(75-193)$ & 72 & 2,004 & $36(28-45)$ & $3.7(2.1-6.3)$ \\
\hline Respiratory disease & 3 & 220 & $14(5-41)$ & 30 & 2,444 & $12(8-18)$ & $1.1(0.3-3.7)$ \\
\hline Diabetes & 2 & 226 & $9(0-31)$ & 9 & 2,473 & $4(2-7)$ & $2.5(0.5-11.5)$ \\
\hline Anemia & 19 & 224 & $85(49-134)$ & 31 & 2,527 & $12(8-17)$ & $6.9(3.8-12.4)$ \\
\hline Depression & 9 & 226 & $40(18-75)$ & 31 & 2,486 & $12(8-18)$ & $3.2(1.5-6.9)$ \\
\hline \multicolumn{8}{|c|}{6 to 12 months after diagnosis } \\
\hline Cardiovascular disease & 8 & 143 & $56(21-112)$ & 52 & 1,841 & $28(21-37)$ & $2.6(1.2-5.9)$ \\
\hline Respiratory disease & 4 & 195 & $21(5-51)$ & 16 & 2,265 & $7(4-11)$ & $2.5(0.8-7.6)$ \\
\hline Diabetes & 1 & 202 & $5(0-30)$ & 13 & 2,298 & $6(3-10)$ & $0.8(0.1-6.5)$ \\
\hline Anemia & 7 & 194 & $36(15-72)$ & 18 & 2,344 & $8(5-12)$ & $5.4(2.1-13.6)$ \\
\hline Depression & 1 & 198 & $5(0-30)$ & 23 & 2,301 & $10(7-15)$ & $0.5(0.1-3.8)$ \\
\hline \multicolumn{8}{|c|}{12 months after diagnosis to total followup } \\
\hline Cardiovascular disease & 29 & 762 & $38(25-55)$ & 292 & 10,594 & $28(24-31)$ & $1.4(0.9-2.1)$ \\
\hline Respiratory disease & 14 & 1,042 & $13(8-22)$ & 78 & 13,491 & $6(5-7)$ & $2.2(0.9-4.0)$ \\
\hline Diabetes & 9 & 1,106 & $8(4-15)$ & 69 & 13,804 & $5(4-6)$ & $1.6(0.8-3.2)$ \\
\hline Anemia & 12 & 1,063 & $11(6-20)$ & 75 & 14,036 & $5(4-7)$ & $2.3(1.2-4.4)$ \\
\hline Depression & 14 & 1,076 & $13(7-21)$ & 91 & 13,655 & $7(5-8)$ & $2.0(1.1-3.7)$ \\
\hline
\end{tabular}

PY: person-years; IR: incidence rate; $95 \%$ CI: $95 \%$ confidence interval; ${ }^{*}$ comorbidity defined as either at least 2 dispensings of a relevant drug or a hospitalization for that condition after soft tissue sarcoma diagnosis.

comorbidities investigated. The highest odds ratio (OR) was found for anemia (OR = 3.6, 95\% CI: 2.4-5.5).

Incidence rates of the comorbidities are presented for three distinct periods of followup time (Table 3). The incidence of cardiovascular disease, anemia and depression was highest during the first six months after STS diagnosis, 124,85 , and 40 per 1,000 person years (py), respectively, and decreased to 38,11 , and 13 per 1,000 py, respectively, in the period of 12 months to total followup. The incidence of respiratory disease and diabetes among STS patients remained stable during followup, ranging from 13-21 per 1,000 py for respiratory disease and 5-9 per 1,000 py for diabetes. Compared to the cancer-free control cohort, STS patients were at increased risk for cardiovascular disease (hazard ratio $(\mathrm{HR})=3.7,95 \% \mathrm{CI}$ : 2.1-6.3), anemia $(\mathrm{HR}=6.9,95 \%$
CI: 3.8-12.4), and depression (HR $=3.2,95 \%$ CI: $1.5-$ 6.9) during the first six months after diagnosis. This risk decreased over time, however, it was still significant for anemia ( $\mathrm{HR}=2.3,95 \% \mathrm{CI}: 1.2-4.4)$ and depression (HR $=2.0,95 \%$ CI: $1.1-3.7)$ in the period of 12 months to total followup. Patients with STS had a similar risk of respiratory disease and diabetes compared to their cancer-free controls during the various followup periods, except for the period 12 months after diagnosis to total followup, where patients with STS had a two times increased risk of respiratory disease (HR $=2.2,95 \%$ CI: $1.3-4.0$ ).

Multivariate analyses were performed to determine the risk factors for developing cardiovascular disease, anemia and depression, that is, the three significantly increased comorbidities after STS diagnosis. Risk factors associated 
TABLE 4: Risk factors for developing cardiovascular disease, anemia, and depression after soft tissue sarcoma diagnosis.

\begin{tabular}{|c|c|c|c|c|c|c|}
\hline \multirow{2}{*}{ Characteristics } & \multicolumn{2}{|c|}{ Cardiovascular disease } & \multicolumn{2}{|l|}{ Anemia } & \multicolumn{2}{|c|}{ Depression } \\
\hline & HR multivariate \# & $95 \% \mathrm{CI}$ & HR multivariate \# & $95 \% \mathrm{CI}$ & HR multivariate \# & $95 \% \mathrm{CI}$ \\
\hline \multicolumn{7}{|l|}{ Gender } \\
\hline Male & 1.9 & $(1.1-3.5)$ & 1.4 & $(0.7-2.8)$ & 1.0 & $(0.4-2.4)$ \\
\hline Female & 1 & reference & 1 & reference & 1 & reference \\
\hline \multicolumn{7}{|l|}{ Age in years } \\
\hline$<50$ & 1 & reference & 1 & reference & 1 & reference \\
\hline $50-<70$ & 0.9 & $(0.4-1.8)$ & 0.7 & $(0.3-1.8)$ & 1.1 & $(0.6-2.4)$ \\
\hline$\geq 70$ & 1.2 & $(0.5-2.5)$ & 0.9 & $(0.3-2.4)$ & 1.5 & $(0.7-3.5)$ \\
\hline \multicolumn{7}{|l|}{ Location } \\
\hline Extremities & 1 & reference & & & & \\
\hline Head and neck & 0.8 & $(0.3-2.0)$ & & & & \\
\hline Thorax & 1.4 & $(0.6-3.1)$ & & & & \\
\hline Abdomen or (retro)peritoneum & 2.1 & $(1.1-4.6)$ & & & & \\
\hline Overlapping sites and NOS & 1.9 & $(0.8-4.7)$ & & & & \\
\hline \multicolumn{7}{|l|}{ Treatment $^{1}$} \\
\hline Surgery & 0.6 & $(0.2-2.3)$ & 0.7 & $(0.2-2.6)$ & & \\
\hline Chemotherapy & 1.7 & $(0.7-4.4)$ & 1.9 & $(1.1-4.1)$ & & \\
\hline
\end{tabular}

NOS: not otherwise specified; HR: hazard ratio; 95\% CI: 95\% confidence interval; \# the multivariate model included all factors that were univariately associated with the outcome; ${ }^{1}$ defined during the first six months after soft tissue sarcoma diagnosis.

with the comorbidity in the univariate analyses are presented in Table 4 and were included in the multivariate analyses. Independent risk factors for cardiovascular disease after diagnosis for STS were male gender $(\mathrm{HR}=1.9,95 \% \mathrm{CI}: 1.1-$ 3.5 ) and STS located in abdomen or (retro)peritoneum (HR $=2.1,95 \%$ CI: 1.1-4.6). The only independent risk factor for developing anemia after STS diagnosis was receiving chemotherapy during the first six months after STS diagnosis $(\mathrm{HR}=1.9,95 \% \mathrm{CI}: 1.1-4.1)$.

\section{Discussion}

To our knowledge, this is the first population-based study to report on the prevalence of concomitant diseases at STS diagnosis and the incidence of comorbidities after STS diagnosis and treatment. We showed that $33 \%$ of the patients with STS suffered from cardiovascular disease (including hypertension) at time of diagnosis, and $10 \%$ had evidence of respiratory disease. Diabetes, anemia, and depression occurred in $6-7 \%$ of the patients at time of diagnosis. In a previously performed study [14] in The Netherlands on comorbid conditions among patients diagnosed with one of the 20 most frequent tumors, similar results were found. In that study cardiovascular disease (including hypertension) was present in $30 \%$ of the patients, respiratory disease in $10 \%$ of the patients and diabetes in $7 \%$ of the patients [14].

In the current study, STS patients were twice as likely to have any of the comorbidities prior to diagnosis compared with the cancer-free control group. This can likely be attributed to several risk factors that are both related to the development of the comorbidity and STS such as immunodeficiency, environmental factors, lifestyle factors, and genetic factors $[8,9]$.
Cardiovascular diseases, anemia, and depression were common incident comorbidities, especially in the first six months after STS diagnosis when rates were 124, 85, and 40 per 1,000 py, respectively, and 3-7 times higher than among cancer-free controls. These incidence rates decreased during followup, which suggests that cardiovascular diseases, anemia and depression are comorbidities related to the cancer itself or its treatment. This was investigated in our risk factor analysis. We found few significant independent risk factors, which might be explained by the relatively small patient cohort as STS is a rare tumor. We did find that male gender and STS located in the abdomen or (retro)peritoneum significantly increased the risk of developing cardiovascular disease after correction for other risk factors. A possible explanation for this finding is that abdominal or (retro)peritoneal STS tumors are mostly larger and of higher stage at presentation than those located elsewhere [10]. This may be due to the fact that these tumors arise in a clinically silent anatomical region where symptoms develop late in contrast to most head and neck tumors, which become clinically evident and symptomatic at a small size. Following this, STS tumors located in the abdomen might compress or invade other vital organs located in the abdomen. Second, treatment of abdominal STS tumors is more invasive and complicated. It is more difficult to successfully provide a complete operative resection, vital organs might be damaged due to the surgery or radiation therapy and following the more advanced stage at diagnosis, relatively more patients will receive chemotherapy [28].

In addition to risk factors for cardiovascular disease, a clear association was demonstrated between chemotherapy in the first six months after STS diagnosis and the risk of anemia during followup. It is well recognized that anemia 
might arise during or shortly after myelotoxic chemotherapy $[29,30]$. Next to chemotherapy, radiation therapy may further negatively impact the severity and incidence of anemia [31]. Unfortunately we did not have data on radiotherapy available for all patients included in our study cohort. A former Dutch study on STS patients in the period 1989-1995 showed that $25 \%$ of the STS patients received radiotherapy with or without surgery and chemotherapy [24]. Analyses with data from a more recent cohort, the linked Eindhoven Cancer Registry-PHARMO cohort [32], showed that about $40 \%$ of the STS patients in the period 2000-2007 received radiotherapy.

Next to missing data on radiotherapy, another study limitation concerns the way the comorbidities were captured. In this study we did not use data from general practitioners or outpatient medical visits. The presence of comorbidities was based on hospitalizations and/or drug dispensings and consequently comorbid cases with a mild course were not included. Furthermore, identifying only the medically treated depression, limits the ability to directly compare these results with studies using structured clinical interviews or screening questionnaires to define depressive disorders. Regarding cardiovascular comorbidity, the definition used is very broad. However, low numbers of the patients included in this study did not allow sub classification of the results. Finally, as STSs are a heterogeneous group of tumors and there is a considerable variation in incidence patterns of sarcomas by histological type and anatomic site [25], future studies with larger patient numbers should focus on determining the comorbidities per histological subtype.

\section{Conclusion}

This study quantifies the significant burden of prevalent comorbidity in patients diagnosed with STS and presents the incidence of comorbidity after STS diagnosis and treatment. Prevalent comorbidity at STS diagnosis implies that more personalized supportive care is required for these patients. Incident comorbidity after diagnosis and treatment provides insight into the pharmacovigilance of STS treatment which can be used to improve the outcome of these patients.

\section{Conflict of Interests}

No conflict of interest declared for L. Overbeek and H. van Boven. M. van Herk-Sukel, F. Penning-van Beest, and R. Herings are employees of the PHARMO Institute for Drug Outcomes Research. This research institute performs financially supported studies for several pharmaceutical companies. S. Shantakumar is an employee of GlaxoSmithKline, RTP, NC, USA and holds GlaxoSmithKline shares.

\section{Acknowledgment}

This study was financially supported by an unrestricted grant from GlaxoSmithKline, RTP, NC, USA. No limitations were set with regard to the conduct of the study and the writing of the paper.

\section{References}

[1] E. C. Borden, L. H. Baker, R. S. Bell et al., "Soft tissue sarcomas of adults: state of the translational science," Clinical Cancer Research, vol. 9, no. 6, pp. 1941-1956, 2003.

[2] F. Berrino, R. De Angelis, M. Sant et al., "Survival for eight major cancers and all cancers combined for European adults diagnosed in 1995-99: results of the EUROCARE-4 study," Lancet Oncology, vol. 8, no. 9, pp. 773-783, 2007.

[3] A. Jemal, R. Siegel, J. Xu, and E. Ward, "Cancer statistics, 2010," CA Cancer Journal for Clinicians, vol. 60, no. 5, pp. 277300, 2010.

[4] Guideline soft tissue sarcoma, In Amsterdam: Nederlandse Werkgroep Weke Delen Tumoren (NWWDT), 2010.

[5] A. N. Van Geel, J. A. M. Van Unnik, R. B. Keus, and I. P. M. Van Beuningen, "Diagnosis and treatment of soft tissue tumours: the Dutch nationwide- accepted consensus," Sarcoma, vol. 2, no. 3-4, pp. 183-191, 1998.

[6] A. N. Van Geel, J. A. Van Unnik, and R. B. Keus, "Consensus soft tissue tumors. Dutch workgroup soft-tissue tumors," Nederlands Tijdschrift voor Geneeskunde, vol. 139, no. 16, pp. 833-837, 1995.

[7] F. Ducimetière, A. Lurkin, D. Ranchère-Vince et al., "Incidence of sarcoma histotypes and molecular subtypes in a prospective epidemiological study with central pathology review and molecular testing," PLoS ONE, vol. 6, no. 8, Article ID e20294, 2011.

[8] K. M. Skubitz and D. R. D’Adamo, "Sarcoma," Mayo Clinic Proceedings, vol. 82, no. 11, pp. 1409-1432, 2007.

[9] G. Ottaviani and N. Jaffe, "The etiology of osteosarcoma," Cancer Treatment and Research, vol. 152, pp. 15-32, 2009.

[10] J. C. Gutierrez, E. A. Perez, D. Franceschi, F. L. Moffat Jr, A. S. Livingstone, and L. G. Koniaris, "Outcomes for Soft-Tissue Sarcoma in 8249 Cases from a Large State Cancer Registry," Journal of Surgical Research, vol. 141, no. 1, pp. 105-114, 2007.

[11] F. Levi, C. La Vecchia, L. Randimbison, and V. C. Te, "Descriptive epidemiology of soft tissue sarcomas in Vaud, Switzerland," European Journal of Cancer, vol. 35, no. 12, pp. 1711-1716, 1999.

[12] H. H. Storm, "Survival of adult patients with cancer of soft tissues or bone in Europe. EUROCARE working group," European Journal of Cancer, vol. 34, no. 14, pp. 2212-2217, 1998.

[13] A. Ferrari, I. Sultan, T. T. Huang et al., "Soft tissue sarcoma across the age spectrum: a population-based study from the Surveillance Epidemiology and End Results database," Pediatric Blood \& Cancer, vol. 57, no. 6, pp. 943-949, 2011.

[14] J. W. W. Coebergh, M. L. G. Janssen-Heijnen, P. N. Post, and P. P. A. Razenberg, "Serious co-morbidity among unselected cancer patients newly diagnosed in the southeastern part of The Netherlands in 1993-1996," Journal of Clinical Epidemiology, vol. 52, no. 12, pp. 1131-1136, 1999.

[15] M. L. G. Janssen-Heijnen, H. A. A. M. Maas, S. Houterman, V. E. P. P. Lemmens, H. J. T. Rutten, and J. W. W. Coebergh, "Comorbidity in older surgical cancer patients: influence on patient care and outcome," European Journal of Cancer, vol. 43, no. 15, pp. 2179-2193, 2007.

[16] M. P. O. Campos, B. J. Hassan, R. Riechelmann, and A. del Giglio, "Cancer-related fatigue: a review," Revista da Associacao Medica Brasileira, vol. 57, no. 2, pp. 206-214, 2011.

[17] E. R. Koomen, A. Joosse, R. M. C. Herings et al., "Is statin use associated with a reduced incidence, a reduced Breslow thickness or delayed metastasis of melanoma of the skin?" European Journal of Cancer, vol. 43, no. 17, pp. 2580-2589, 2007. 
[18] V. O. Dezentjé, N. J. C. Van Blijderveen, H. Gelderblom et al., "Effect of concomitant CYP2D6 inhibitor use and tamoxifen adherence on breast cancer recurrence in early-stage breast cancer," Journal of Clinical Oncology, vol. 28, no. 14, pp. 2423$2429,2010$.

[19] E. R. Koomen, A. Joosse, R. M. C. Herings, M. K. Casparie, H. J. Guchelaar, and T. Nijsten, "Does use of estrogens decrease the Breslow thickness of melanoma of the skin? Oral contraceptives and hormonal replacement therapy," Melanoma Research, vol. 19, no. 5, pp. 327-332, 2009.

[20] http://www.dutchhospitaldata.nl/, 2010.

[21] E. A. Mesri, E. Cesarman, and C. Boshoff, "Kaposi's sarcoma and its associated herpesvirus," Nature Reviews Cancer, vol. 10, no. 10, pp. 707-719, 2010.

[22] The International Agency for Research on Cancer, C. D. M. Fletcher, K. Krishnan Unni, and F. Mertens, Eds., WHO Classification of Tumours: Pathology and Genetics of Tumours of Soft Tissue and Bone, IARC, Lyon, France, 2002.

[23] C. D. M. Fletcher, J. J. Berman, C. Corless et al., "Diagnosis of gastrointestinal stromal tumors: a consensus approach," International Journal of Surgical Pathology, vol. 10, no. 2, pp. 81-89, 2002.

[24] P. H. A. Nijhuis, M. Schaapveld, R. Otter, W. M. Molenaar, W. T. A. Van Der Graaf, and H. J. Hoekstra, "Epidemiological aspects of soft tissue sarcomas (STS)-consequences for the design of clinical STS trials," European Journal of Cancer, vol. 35, no. 12, pp. 1705-1710, 1999.

[25] J. R. Toro, L. B. Travis, J. W. Hongyu, K. Zhu, C. D. M. Fletcher, and S. S. Devesa, "Incidence patterns of soft tissue sarcomas, regardless of primary site, in the Surveillance, Epidemiology and End Results program, 1978-2001: an analysis of 26,758 cases," International Journal of Cancer, vol. 119, no. 12, pp. 2922-2930, 2006.

[26] C. Wibmer, A. Leithner, N. Zielonke, M. Sperl, and R. Windhager, "Increasing incidence rates of soft tissue sarcomas? A population-based epidemiologic study and literature review," Annals of Oncology, vol. 21, no. 5, pp. 1106-1111, 2009.

[27] N. E. Breslow and N. E. Day, "Statistical methods in cancer research. Volume II-the design and analysis of cohort studies," IARC Scientific Publications, no. 82, pp. 1-406, 1987.

[28] M. A. Clark, C. Fisher, I. Judson, and J. Meirion Thomas, "Soft-tissue sarcomas in adults," New England Journal of Medicine, vol. 353, no. 7, pp. 701-711, 2005.

[29] J. E. Groopman and L. M. Itri, "Chemotherapy-induced anemia in adults: incidence and treatment," Journal of the National Cancer Institute, vol. 91, no. 19, pp. 1616-1634, 1999.

[30] F. Tas, Y. Eralp, M. Basaran et al., "Anemia in oncology practice: relation to diseases and their therapies," American Journal of Clinical Oncology, vol. 25, no. 4, pp. 371-379, 2002.

[31] L. B. Harrison, D. Shasha, C. White, and B. Ramdeen, "Radiotherapy-associated anemia: the scope of the problem," Oncologist, vol. 5, supplement 2, pp. 1-7, 2000.

[32] M. P. P. van Herk-Sukel, L. V. van de Poll-Franse, V. E. P. P. Lemmens et al., "New opportunities for drug outcomes research in cancer patients: the linkage of the Eindhoven Cancer Registry and the PHARMO Record Linkage System," European Journal of Cancer, vol. 46, no. 2, pp. 395-404, 2010. 


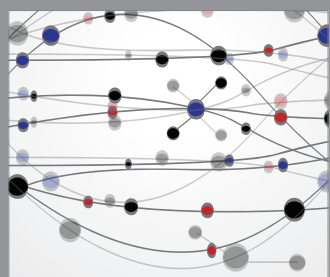

The Scientific World Journal
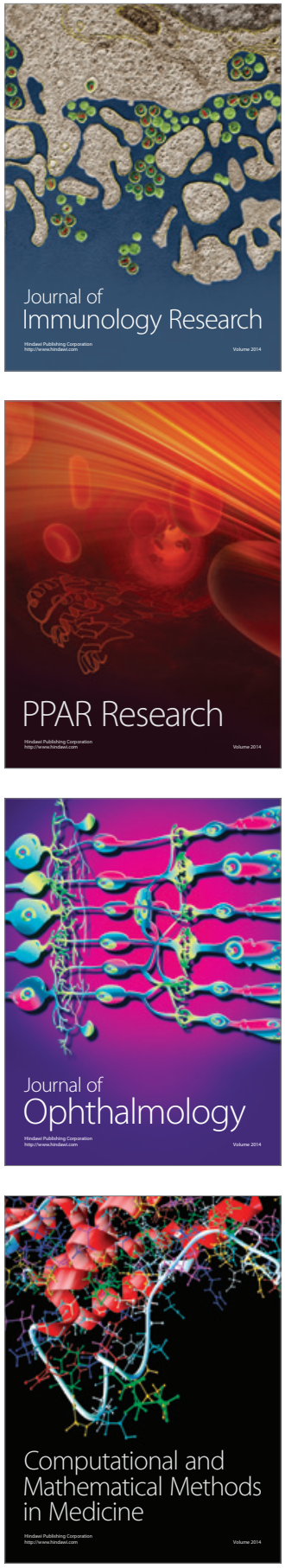

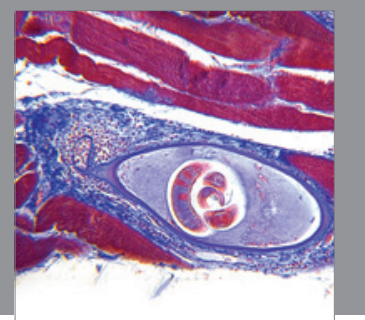

Gastroenterology

Research and Practice
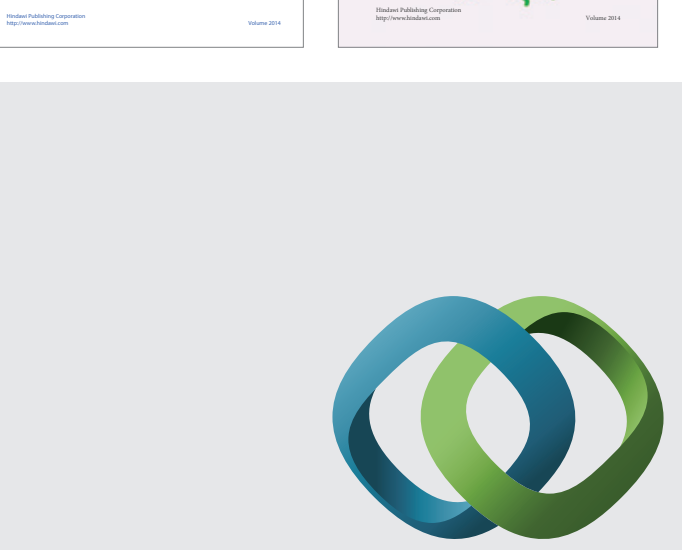

\section{Hindawi}

Submit your manuscripts at

http://www.hindawi.com
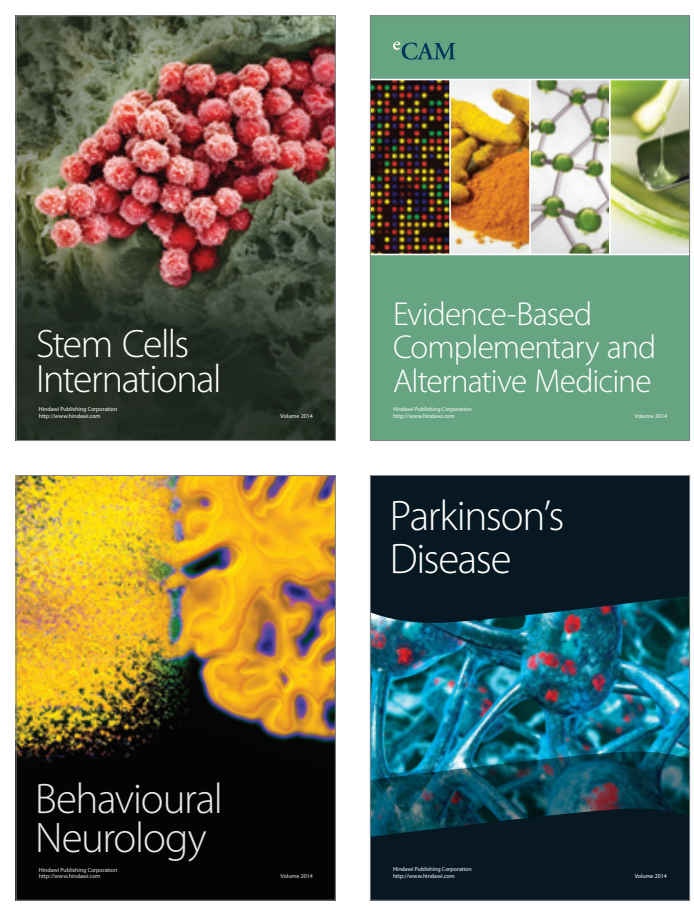

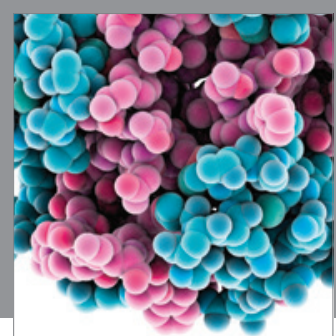

Journal of
Diabetes Research

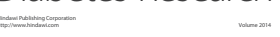

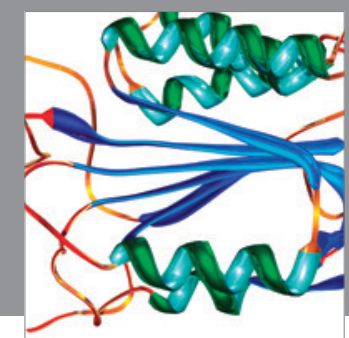

Disease Markers
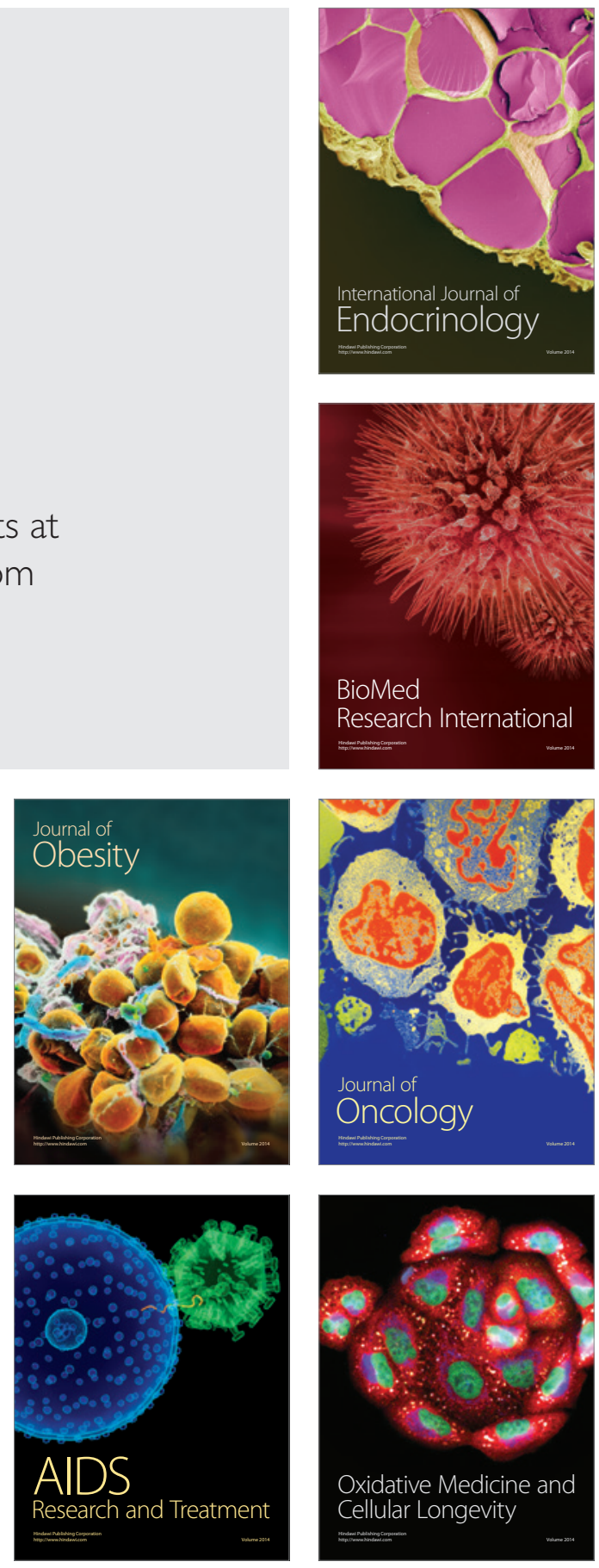